\title{
Study on introduction of Cerasus clarofolia in Huangshan
}

\author{
Nan Cheng-hui ${ }^{1}$, Xue Xiao-ming ${ }^{1}, X$ ie Chun-ping ${ }^{1}$, Yi Xian-gui ${ }^{2}$, Wang Xian-rong ${ }^{2}$ and Tang Geng-guo ${ }^{2}$ \\ ${ }^{1}$ Nanjing Forest Police College, Nanjing 210023, China \\ ${ }^{2}$ Nanjing Foresty University, Nanjing 210037, China \\ Author's brief introduction: Nan Cheng-hui (1982-), male, from Ruzhou, Henan Province, Ph.D., lecturer, mainly engaged in \\ dendrology and plant taxonomy, Tel:18951853461, E-mail: 306375895@qq.com.
}

\begin{abstract}
In this paper, the habitat of Cerasus clarofolia was investigated and analysed, under natural conditions the growth of Cerasus clarofolia is influenced by low temperature of winter. The seeds of Cerasus clarofolia need low-temperature to germination. The seedling with 4 leaves grew well after introduction, the survival rate reached $79.7 \%$. Planting with clear water was found easier to take roots, the roots were come from the lenticels, under diffent environmental conditions, the lenticels formed morphological, physiological differences are the important factors take roots for Cerasus.
\end{abstract}

\section{Introduction}

Cerasus clarofolia of Rosaceae is a wild cherry flower originating in China. According to the investigation of Cerasus clarofolia in Huangshan, Anhui and Badong County, Hubei, it was found that most of the Cerasus clarofolia were small trees or shrubby trees with a height not exceeding $10 \mathrm{~m}$; its trunk was rough and densely furrowed. Inflorescences umbellate or subumbellate, 2-4flowered; involucral bracts brown, spatulate, abaxially glabrous, adaxially pilose; peduncle $4-10 \mathrm{~mm}$, glabrous or pilose; bracts green, subovate, ovate-oblong, or suborbicular, persistent in fruit, margin serrate, teeth with a conical to capitate apical gland. Flowers opening at same time as leaves. Hypanthium campanulate, outside glabrous or nearly so. Sepals ovate-triangular to lanceolate-triangular, margin glandular serrate or entire, apex acute to acuminate. Petals white or pink, obovate to suborbicular. Drupe red, ellipsoid. Fl. Apr-Jun, fr. Jun-Jul. Forests or thickets on mountain slopes; $800-3600 \mathrm{~m}^{[1]}$.

Compared with other wild cherry resources, Cerasus clarofolia has better self-reproductive ability. During the field investigation in Huangshan Mountain, Anhui Province, it was found that there were dozens of 1-3-yearold seedlings under the wild Cerasus clarofolia trees, among which annual seedlings were the most, accounting for more than $90 \%$; but in summer and autumn, the upper canopy of Cerasus clarofolia trees was more than $90 \%$. The canopy closure resulted in a large number of death of seedlings of Cerasus clarofolia. At present, there are few reports on the introduction of Cerasus clarofolia ${ }^{[2-4]}$. In some places, the ornamental and ecological values of wild cherry resources such as Cerasus clarofolia are not well understood, and the phenomenon of destroying Cherry Blossom forests and planting other forests appears. In order to protect the wild resources of Cerasus clarofolia, the authors conducted a preliminary experiment on the introduction and observation of annual seedlings of Cerasus clarofolia in Huangshan, Anhui Province, in order to provide experimental basis for the development and utilization of Cerasus clarofolia.

\section{Survey overview and introduction methods}

\subsection{Introduction land survey}

Huangshan, located in the south of Anhui Province, is a subtropical monsoon climate zone with warm, humid, abundant rainfall and excellent natural conditions. The annual average temperature is $7.9^{\circ} \mathrm{C}$, the annual average rainfall is $2369.3 \mathrm{~mm}$, and the annual average relative humidity is $70 \%$. The topography of Huangshan Mountain is complex and the climate varies obviously with the altitude; the four seasons are distinct under the line of Banshan Temple and Yungu Temple; only 140 days are spent in spring, summer and autumn, and the rest is winter ${ }^{[5]}$.

Because of the deep mountains and valleys, coupled with the vertical change of climate and the special Mountain Microclimate with local complex topography, more environmental choices are provided for the growth of plants.

\subsection{Introduction method}

The field habitats of Cerasus clarofolia in Huangshan were investigated, and the dense seedlings of next year's seedlings were selected for introduction.

In May 2009, 300 seedlings with 3-6 true leaves were introduced from the vicinity of the Yellow Sea in Huangshan and transplanted into the nursery stock pit pan 
of the laboratory of Nanjing Forestry University. The cultivation medium was mixed soil composed of rotten leaf soil, nutrient soil, perlite and vermiculite (3:3:1); sunlight was illuminated for about 4 hours a day at room temperature and shaded for 6-10 hours. Darkness 10-14 hours. The growth of seedlings was observed regularly, and the values of seedling height, base diameter, true leaf number and leaf area etc. were measured and recorded (the measured leaves were completely unfolded true leaves 2 leaves apart from the top of seedlings). The height growth of seedlings stopped transplanting in the field.

The cuttings of Cerasus clarofolia with apical buds were selected as cuttings. The length of cuttings was 15$20 \mathrm{~cm}$, and 3-4 true leaves were left at the upper end. The cuttings were cut in clear water at room temperature. The lower end of cuttings was cut into horseshoe shape without any hormone treatment. The growth of cuttings was observed and recorded. Under the same conditions, the control experiment was conducted with Cerasus subhirtella var. ascendens.

\section{Results and analysis}

\subsection{Effect of low temperature on seed dormancy}

During the field investigation of Cerasus clarofolia in Huangshan, it was found that the seedlings of Cerasus clarofolia were mostly distributed in the Cerasus clarofolia forests with altitudes of 1000-1600 M. With the increase of altitude, the number of seedlings of Cerasus clarofolia increased gradually. When the altitude was about $1600 \mathrm{~m}$, the number of Cerasus clarofolia seedlings reached the maximum, reaching hundreds, and even reaching the maximum under some forests. With the decrease of altitude, the number of seedlings of Cerasus clarofolia decreased gradually to below $1000 \mathrm{~m}$, and no Cerasus clarofolia big trees and seedlings were found. Big trees of Cerasus clarofolia are often associated with deciduous trees such as Quercus stewardii, Maddenia incisoserrata, Tilia japonica, Carpinus cordata var. Chinensis, etc. which form a unique deciduous broadleaved forest at the top of the mountain. In the West Sea and Tianhai of Huangshan altitude about $1600 \mathrm{~m}$. There are more Cerasus clarofolia in the vicinity.

In addition to the mechanical inhibition of endocarp, physiological dormancy is also one of the reasons why cherry seeds can not germinate. Under artificial conditions, in order to break the dormancy of plant seeds, lowtemperature sand storage is a commonly used method, and different plant seeds have different time for lowtemperature sand storage. However, under the conditions of winter, plant seeds break dormancy and complete the regeneration of their offspring. According to the investigation of the habitat of Cerasus clarofolia, the number of seedlings of Cerasus clarofolia increased with the increase of altitude, while the temperature decreased with the increase of altitude, indicating the effect of temperature on seed germination. The intensity and time of low temperature in winter in high altitude area control the germination of the seeds of Cerasus clarofolia, forming a unique part of the distribution area of Cerasus clarofolia, while in the low altitude area below $1000 \mathrm{~m}$ in Huangshan, because of the insufficient intensity and time length of low temperature in winter, there is no wild seedling to big tree formation; Cerasus clarofolia seeds need low temperature seeds, which have winter dormancy characteristics.

\subsection{Analysis of observation result of seedling growth}

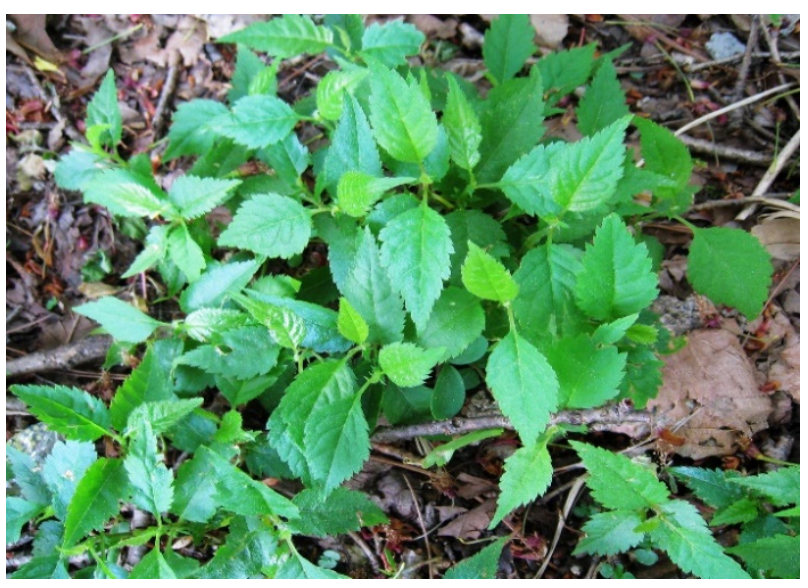

Fig.1. Before introduction

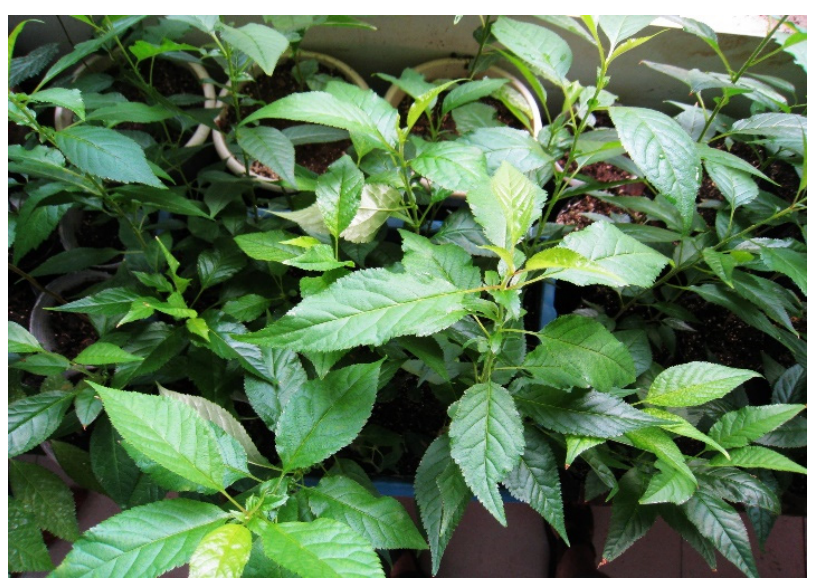

Fig.2. Four months after introduction

Introduction of Cerasus clarofolia as an annual seedlings, transplanting With 3-6 different number of true leaves, the first pair of true leaves in the opposite shape, the third began to become alternate. After transplanting in the laboratory, the seedlings were delayed for about a week and began to grow normally After transplanting, the average seedling height in the aboveground part was $4.4 \mathrm{~cm}$, the average basal diameter Was $1.07 \mathrm{~mm}$, the average true leaves were 4 , and the average leaf area was $419.6 \mathrm{~mm}^{2}$ (Fig.1). After four months of growth, seedlings stopped growing high, the average seedling height was $40.5 \mathrm{~cm}$, the average branch diameter was $3.71 \mathrm{~mm}$, the true number of leaves reached 29 , and the average leaf area was $3740.8 \mathrm{~mm}^{2}$ (Fig.2). After five months of transplantation the seedlings survived 239 plants. With a survival rate of $79.7 \%$. Specific growth values of seedling height, branch diameter, leaf area and leaf number are shown in table 1 . 
Table 1. Growth observation table

\begin{tabular}{ccccc}
\hline $\begin{array}{c}\text { Measurement } \\
\text { date }\end{array}$ & $\begin{array}{c}\text { Height of } \\
\text { seedling } \\
\text { /cm }\end{array}$ & $\begin{array}{c}\text { Branch of } \\
\text { diameter } \\
/ \mathrm{mm}\end{array}$ & $\begin{array}{c}\text { Leaf area } \\
/ \mathrm{mm}^{2}\end{array}$ & $\begin{array}{c}\text { Leaf } \\
\text { number }\end{array}$ \\
\hline 2012.5 .13 & $2.8-5.6$ & $0.90-1.28$ & $195-628$ & $3-6$ \\
2010.6 .13 & $10.0-27.1$ & $1.40-1.98$ & $799-1253$ & $11-15$ \\
2010.7 .13 & $15.0-40.5$ & $1.40-2.80$ & $2112-2961$ & $13-22$ \\
2010.8 .13 & $16.0-71.0$ & $2.26-3.56$ & $3143-4681$ & $17-31$ \\
2010.9 .13 & $16.0-74.0$ & $2.84-3.88$ & $3048-4708$ & $20-36$ \\
2010.10 .13 & $16.0-74.0$ & $3.00-4.10$ & $3048-4708$ & $20-36$ \\
\hline
\end{tabular}

From the five-month growth process of Cerasus clarofolia, it can be seen that the annual seedlings of Cerasus clarofolia grew well and the survival rate was higher during the whole observation process. The average seedling height increased from about $4.4 \mathrm{~cm}$ after transplanting to about $40.5 \mathrm{~cm}$ five months later, among which the highest seedling height reached $74.0 \mathrm{~cm}$, showing obvious high growth. The branchl diameter grew slowly and did not change significantly. Similar to other species of Cerasus, the first pair of true leaves of Cerasus clarofolia are opposite, with an average leaf area of about $419.6 \mathrm{~mm}^{2}$, which reaches the maximum three months after transplantation, and the single leaf area changes little at three to five months. The leaf number increases gradually with the growth of seedling height and stops at the height growth stop. A broken line diagram was drawn for the average monthly growth of seedling height, basal diameter and leaf number of Cerasus clarofolia ( Fig. 3). It was found that the growth of Cerasus clarofolia seedling height and true leaf number gradually stopped at four months, and the high growth was proportional to the true leaf number. The change of basal diameter was small, and the growth continued after the high growth stopped. Compared with the change of seedling height and true leaf number in the whole growth process, the growth was relatively stable. From the perspective of the whole introduction experiment, Cerasus clarofolia is a kind of wild Cerasus resource that is easy to conduct the introduction of solid seedlings. The slow seedling stage is short, the survival rate is high, and there is no adverse growth reaction in the growth process.

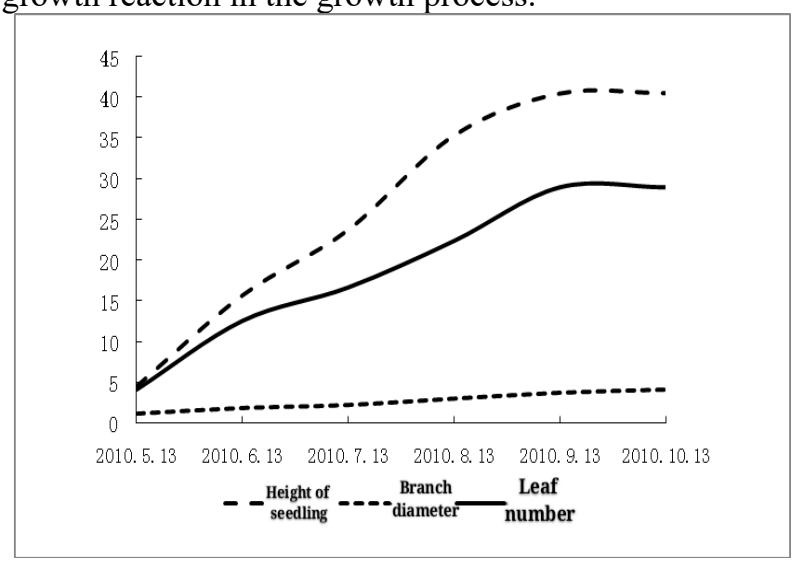

Fig. 3. Relationship between the average monthly growth of the seedling height, branch diameter and leaf number

\subsection{Comparative analysis of clearwater cutting}

When softwood cutting of Cerasus clarofolia in water for about a week, white tuberculous roots were produced from some dermal holes under the cuttings(Fig. 4), and about 20 days later, the tuberculous roots grew to about $0.5 \mathrm{~cm}$, and the root tips became yellowish brown. At this time, transplanting was carried out, and the survival was good. After about five months of transplanting, the upper leaves of the cuttings fell off, and the growth of Cerasus clarofolia stopped. Observation showed that the root length of the cuttings was $5-18 \mathrm{~cm}$, turning into yellowish brown, and the growth was good(Fig. 5). Under the same condition, the experiment of Cerasus subhirtella var. ascendens didn't take root. When softwood cutting of Cerasus subhirtella var. ascendens in water for about 30 days, the cuttings turned brown and died.

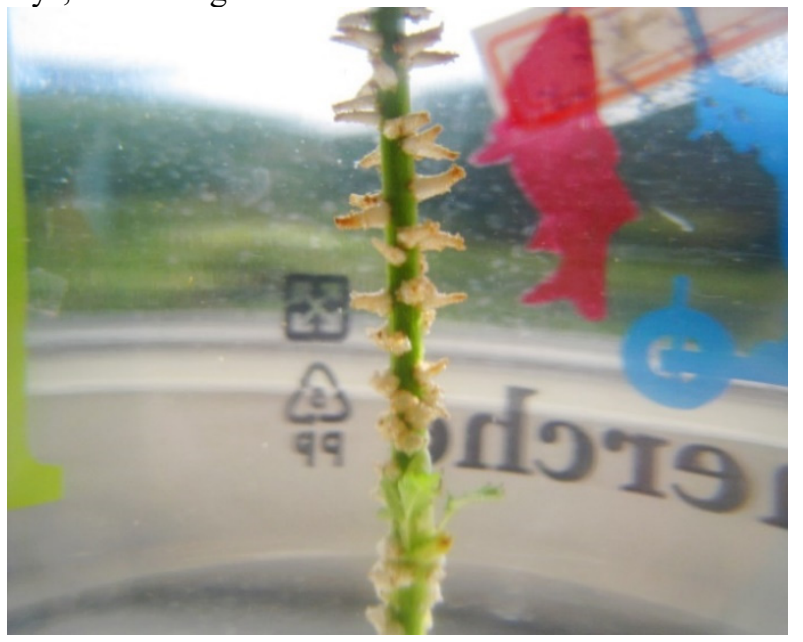

Fig. 4. 20 days after Cutting in clear water

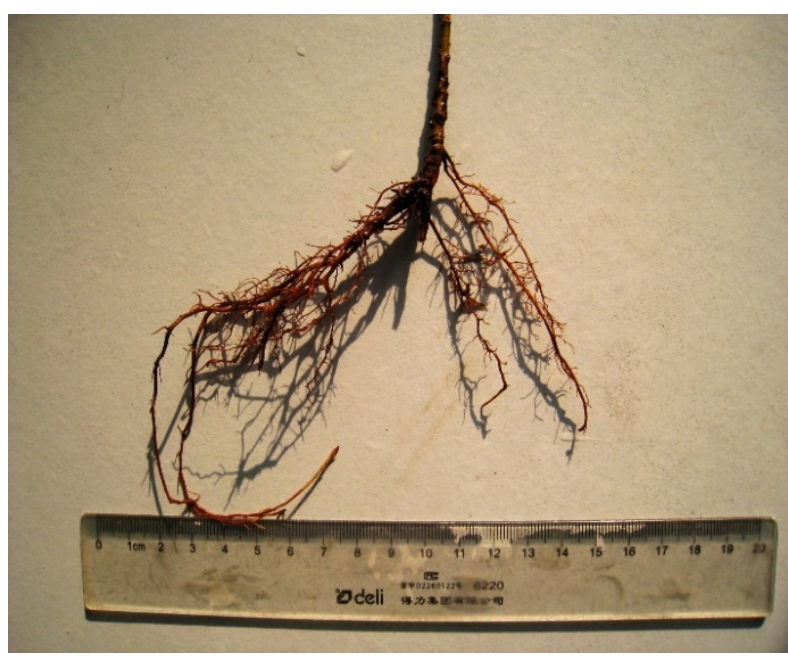

Fig. 5. 150 days after transplantation

The softwood cuttings selected in the water cutting experiment were originally produced in the high-altitude area with high humidity in Huangshan, where the growth conditions were relatively harsh, the trunk was relatively rough, the transverse dermal hole was obviously protruding, and there were many advection buds on the trunk. The softwood cuttings of Cerasus subhirtella var. ascendens selected in the comparative experiment were 
taken from Baohua mountain in Jurong, Jiangsu province. The growth altitude was relatively low, the humidity was small, the trunk was smooth, and the derm protrusion was not obvious. Combined with the experimental selection of two kinds of cherry water cuttage rooting difficult and cherry hole rooting type, it is concluded that the environmental conditions of the original place of cherry plants formed by the pore morphology, physiological differences are important factors affecting the rooting of cherry plants cutting reproduction. Was born in humidity, relatively high altitude region, skin cells in the exercise of respiration under the hole and the exercise of absorb the moisture and nutrients in damp environment, resulting in the Cerasus clarofolia branches lenticel wild state of protuberant, dry tumor more external form, thus cutting water Cerasus clarofolia can be absorbed by cells under the skin pore water and nutrients for growth, so as to exercise the function of root, and then gradually evolved adventitious roots; However, due to the differences in environmental conditions, the Cerasus subhirtella var. ascendens selected from Baohua mountain, Jurong, Jiangsu province mainly relies on roots to absorb water and nutrients in the wild state. The trunk is smooth and the dermal processes are not obvious. Combining Wang Xianrong on the Cerasus serrulata var. lannesiana 'Speciosa', Cerasus yedoensis'Somei-yoshino', Cerasus subhirtella 'Pendula' in aquatic cutting test in cherry blossoms, such as the skin of the cuttings hole type roots, plants of the genus speculated that cherry stems cells under the skin hole of under the stress of damp or stimulation such as aquatic environment in addition to the exercise of respiration, also have the function of the absorb water and nutrients, which can be developed into adventitious roots, the natural environmental conditions of different also contributed to the skin cell function under the hole absorb water and nutrients, was born in poor soil and moist environment under the plants of the genus sakura lenticel cells, has the stronger absorption function of water and nutrients, thus has strong ability of into adventitious roots, The evidence needs further study.

\section{Conclusion and discussion}

Under natural conditions, the difference in the number of actual seedlings in the Cerasus clarofolia forest caused by different altitude is essentially the effect of different winter low temperature intensity and time length caused by different altitude on the germination rate of Cerasus clarofolia seeds in the field. The most seedlings were found under the forest at an altitude of about $1600 \mathrm{~m}$ in Huangshan area, which showed that the time length and intensity of low temperature in winter in the area with an altitude of about $1600 \mathrm{~m}$ in Huangshan is the best temperature condition for breaking dormancy of Cerasus clarofolia seeds, therefore, during the seed propagation and introduction of the Cerasus clarofolia ,artificial simulation can be carried out according to the winter low temperature and soil moisture in this area.

The seedlings of Cerasus clarofolia with about 4 true leaves were artificially introduced in the high altitude area of Huangshan. During the observation period of five months, the growth was good, the slow seedling period was short, and the survival rate was high, reaching $79.7 \%$. After being transplanted in the field in autumn, it can survive the winter smoothly and has good cold resistance. It is an easy wild cherry blossom resource to be introduced. The seedlings of Cerasus clarofolia introduced in Nanjing germinated late in early April, so the successful introduction of Cerasus clarofolia can greatly extend the whole sakura viewing season and enrich the existing sakura viewing resources .

Experiments on water cutting of Cerasus clarofolia showed that Cerasus clarofolia was a type of pit rooting which was easy to take root. It was inferred that under the stress of humid and cold environment, the cells under the dry pit of Cerasus clarofolia could absorb water and nutrients as well as root, so it was easy to form at the pit under the stress of clear water. Adventitious roots are easy to survive in water. This experiment also shows that the external environment conditions have certain effects on the adventitious rooting of the cells under the dermis of cherry plants. The cherry plants grown in poor soil and humid and cold air environment have obvious dermis, rough branches and more sprouting branches. The cells under the dermis can absorb nutrients and water. Because of its strong ability to evolve into adventitious roots, it is easy to introduce and survive. The relevant evidence needs further study.

\section{Fund project:}

Basic scientific research project funded by central university (No.: LGYB201703).

\section{References}

1. Yü, T. T., Lu, L. T., Ku, T, C., Li, C. L. \& Chen, S. X., Rosaceae. In: Yü, T. T. (ed.), Flora Reipublicae Popularis Sinicae, 38: 41-89, Science Press, Beijing(1986)

2. Chen, Z. W., Wang X. F., Yi X. G. \& Wang, X. R., A preliminary study on the in vitro culture of Cerasus clarofolia, Journal of Forest and Environment, (4): 349-353(2011)

3. Chen Z. W., YI X. G., Wang X. R., Xie C. P., Nan C. H. \& Wang X. F., Niche characteristics of dominant population of Cerasus clarofolia community in Huangshan Mountain, Journal of Nanjing Forestry University(Natural Sciences Edition), (S1):3946(2014)

4. Nan C. H., Xue X. M., Yi X. G., Wang X. R.\& Tang G. G., Studies on Rapid Micropropagation System of Cerasus discoidea, Jiangsu Agricultural Sciences, (1):48-52(2019)

5. Hu J. Q., Liang S. W.. Huangshan plants, Fudan University Press, (1996) 